\title{
Evaluating White Space of a Malaysian Secondary ELT
}

\section{Textbook}

\author{
$\mathrm{Ng} \mathrm{Yu} \mathrm{Jin}$ \\ doi:10.7575/aiac.alls.v.1n.2p.220
}

\begin{abstract}
Students are believed to learn at optimum level with materials with a lot of white space since the existence of vast number of words and limited amount of white space, especially in textbooks may contribute to the increase in anxiety among learners (Tomlinson, 1998). This study evaluates the amount of white space in terms of pixels in the Malaysian KBSM Form 2 English textbook using MATLAB 7.5. The findings reveal the inadequacy of white space in terms of pixels in our local textbooks. Not many pages have the percentage of white space exceeding 90 percent which is believed to be the ideal on a page. Hence, this method of evaluation can aid textbooks writers or evaluators to create textbooks that are less threatening so that learning a language with textbooks might just be productive to both learners and educators.
\end{abstract}

\section{Introduction}

Textbooks are undisputed essential components in most language programs which serve as the basis for much of the language input learners receive and the language practice that takes place in the classroom. In some situations, the textbook may function as a supplement to the teacher's instruction in the ESL 
teaching and learning process. For most teachers, textbooks provide the foundation for the content of lessons, the balance of the skills taught, as well as the kinds of language practice the students engage in during class activities. Despite having a national standardized examination of 'Sijil Pelajaran Malaysia' (SPM) for the secondary 5 students and 'Penilaian Menengah Rendah' for the secondary 3 students, the textbooks are developed differently for the different zones in Malaysia. The Malaysian government provides students free textbooks. As quoted from the New Straits Times dated $10^{\text {th }}$ March 2007, the Malaysian Education Minister pointed out that 97 per cent of the five million student population were already enjoying the benefit". Hence, teachers do not have the authority to decline the use of the textbooks. This is very much the situation in most Third World countries where the vast majority of teachers have textbooks suggested, prescribed, or assigned to them (Garinger, 2001). Although the state sponsored textbooks are controlled and overseen by the authorities, the element of cost-saving has revealed that free textbooks actually come with hidden costs (Mukundan, 2003). These stated-sponsored materials are believed to be developed in an ad hoc manner (Mukundan, 2003, 2006, 2007).

Materials undoubtedly should achieve impact to attract learners' curiosity, interest and attention (Tomlinson, 1998). The textbooks have failed to attain novelty, variety, attractive presentation and appealing content. Somehow the books are rejected both by teachers and learners as they are not appealing enough to be part of the classroom language learning. Thus, attractive colours, white space and eyecatching photographs should be well inserted and spread through-out the textbooks (Tomlinson, 1998). The more varied choice of topics, texts and 
activities, the more likely is the achievement of impact. Other than that, materials ought to help learners to feel at ease. Relaxed and comfortable students apparently can learn more in shorter periods of time (Dulay, Burt, \& Krashen, 1982). If there is ample white space in the pages, feelings of comfort and assurance will be attained by learners. Limited white space in the text book discourages students to proceed further as psychological barriers hinder them.

\footnotetext{
Materials can help learners to feel at ease in a number of ways. For instance, most learners will feel more comfortable with materials with lots of white space than they do with materials in which lots of different activities are crammed together on the same page. Amount of white space in texts is important to reduce anxiety among readers. The better or more white space in a particular text, the lesser the level of anxiety of the readers. (Tomlinson, 1998, p. 8)
}

The amount of white space in a given page can be analysed and data about the page can be obtained in terms of percentage. With the pre-written MATLAB program, material developers are able to ensure the percentage of white space available on the pages is high. By diminishing the anxiety level of students through significant amount of white space, learning can be facilitated.

\section{Objectives of the Study}

This research is conducted to explore the effectiveness of white space distribution of textbooks. The study includes the thorough analysis of the amount of white space in the textbooks. The quantity of white space is important as it may determine students' anxiety level when using the books. The objectives are as follows: 
1. To evaluate the amount of white space in every page in the textbooks in terms of percentage in pixel using MATLAB 7.5.

2. To determine whether MATLAB 7.5 contributes towards white space evaluation of local textbooks in a more diagnostic manner.

\section{White space in ELT Materials}

It is apparent that students' motivation and attitude levels differ and textcongested pages might affect their anxiety levels. For the purpose of this study, the coloured pictures from the original books are converted into the black and white properties. They are presumed as the non-white space elements that take up the space of the page. They are considered as 'texts' that aggravate students' stress level while reading or using the texts. The area of the page which is not written on with texts or graphics is referred to as white space. The empty areas or blank spaces on the pages are considered as white space. The white spaces on the pages are measured in pixel using the MATLAB software. The formula is formed using the simple percentage formula:

Percentage of White Space $=\frac{\text { Area covered with remaining white pixels } \times 100 \%}{\text { Area covered with only white pixels }}$

No research has been done empirically to evaluate the properties of white space in materials using software. Hence, this research is a new and innovative scope of study as advocated by Brian Tomlinson (2008) in his email to the researchers.

The amazing thing is that I don't know of any empirical research investigating the effects of white space on language acquisition. Most experts seem to 
acknowledge that it facilitates acquisition by increasing clarity and reducing stress but nobody seems to have taken the trouble to verify this empirically. (Tomlinson, 2008)

\section{Methodology}

\section{The Use of MATLAB Software and Its Characteristics}

MATLAB is the abbreviation of Matrix Laboratory. It is a programming language for technical computing from The Math Works, Natick, MA (www.mathworks.com). Used for a wide variety of scientific and engineering calculations, especially for automatic control and signal processing, MATLAB runs on Windows, Mac and a variety of Unix-based systems. Developed by Cleve Moler in the late 1970s and based on the original LINPACK and EISPACK FORTRAN libraries, it was initially used for factoring matrices and solving linear equations. Moler commercialized the product with two colleagues in 1984 . MATLAB is also noted for its extensive graphics capabilities. It is used in this study for the purpose of image processing to calculate the page layout distribution through-out the white space or blank areas of the pages on the textbooks.

\section{Data Collection Procedure}

The process involves scanning, analysing and examining the amount of white space in a page empirically. The MATLAB software is able to calculate the percentage of white space on a page in terms of pixels. Pixel is the smallest point or unit of a picture. MATLAB is chosen as it is the most reliable tool to perform all sorts of analysis in terms of calculation. The program is written using the $\mathrm{C}$ programming language. The programming used is user friendly and able to transform the 'engineering' language into simple layman terms. Validity and 
reliability of this software is proven as it is commercially used by engineers in various engineering fields. The procedure began with the scanning of the texts which were immediately converted into Joint Photographic Experts Group format (JPEG File, .JPG file). Minimal rectification and correction was done to the distorted pages. The software is designed to do all sorts of computing calculation as well as image processing. Multiple matrixes are used to ensure its accuracy as the matrixes are 3 dimensional. Hence, it is suitable to determine to the amount of white space of JPG format texts with absolute accuracy.

\section{Results and Discussion}

\section{Analysis of the Percentage of White Space in the Textbook}

The mean of each chapter is obtained as to find out which chapter has the most white space percentage. White space percentage of each chapter can be calculated using the calculator by adding up all the percentages of white space of each page on the chapter. The percentage of each chapter is shown in Table 1. Figure 1 shows the least white percentage text with only $66.14 \%$ according to the MATLAB software. The highest percentage of white space acquired from this analysis using MATLAB Software is $93.71 \%$ is shown in Figure 2. The overall percentage of this textbook is $85.06 \%$.

Table 1: Average of Percentage of White Space by Chapter

\begin{tabular}{cccc}
\hline Chapter & Percentage (\%) & Chapter & Percentage (\%) \\
\hline 1 & 81.14 & 9 & 86.07 \\
2 & 85.63 & 10 & 85.73 \\
3 & 85.87 & 11 & 85.62 \\
4 & 85.84 & 12 & 86.17 \\
5 & 87.83 & 13 & 79.14 \\
6 & 83.78 & 14 & 85.36 \\
7 & 84.78 & 15 & 88.07 \\
8 & 84.89 & & \\
\hline
\end{tabular}




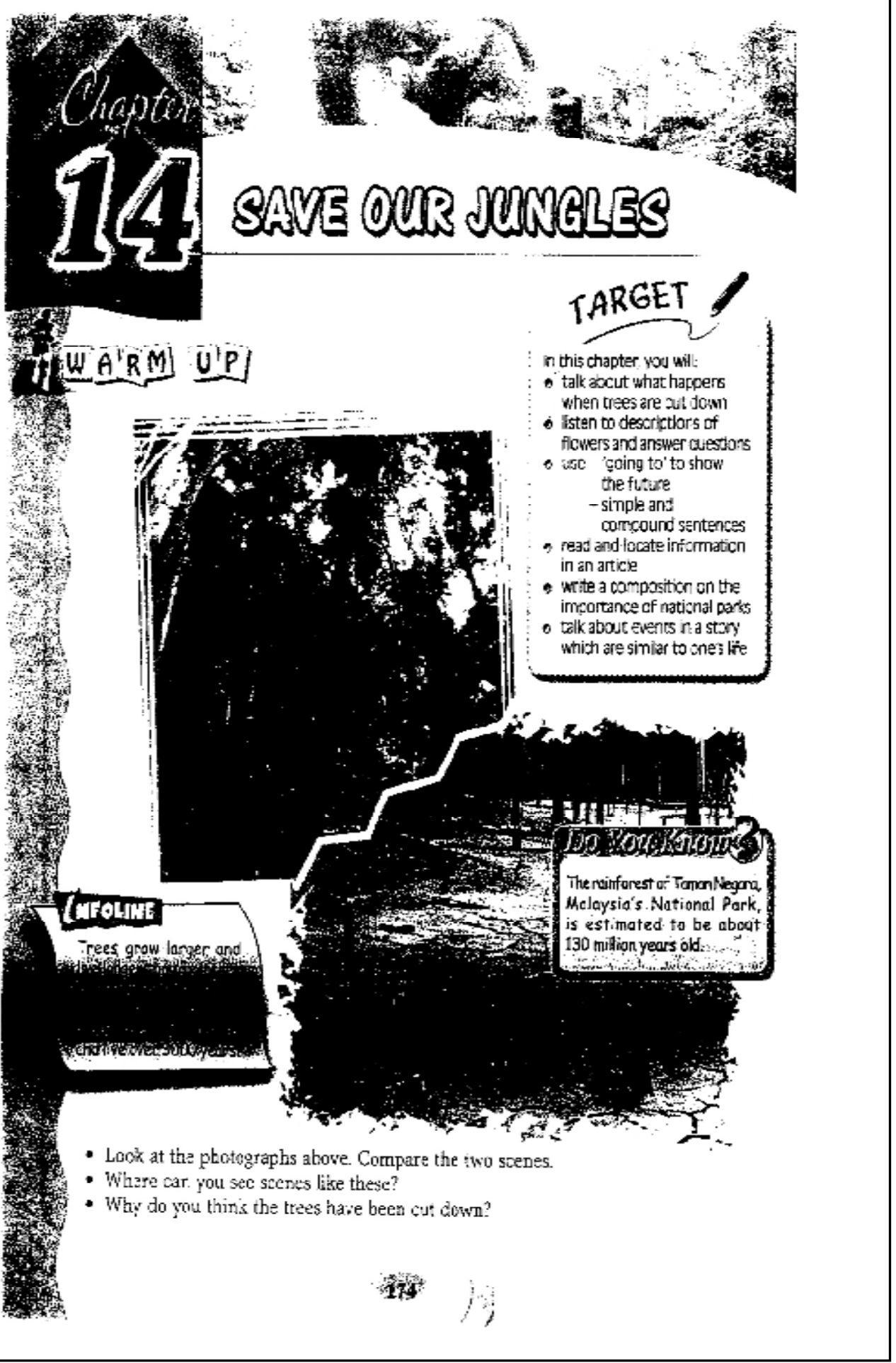

Figure 1: Lowest Percentage White Space Page (66.14\%) 
1 What is the common remedy for the skin problems mentioned in the text?

2 What are the three remedies common to most of these ailments and problems?

3 The following are fluids except
A water
B fruit juice
C porridge
D beverage

4 What are the symptoms of dandruff?

5 Say whether these statements are true or faise.

(a) Acne usually affects young people.

(b) For high fever, drink warm, salt water.

(c) Body odour is unpleasant.

(d) A good diet helps us stay healthy.

TASK 2: Word Chest

(a) Find the meanings that match the words below

Words

1 odour

(winn

2 fluids

s.....

3 inflamed

4

4 special

$$
5 \text { flakes }
$$

5 flakes

6 aches

ariseger

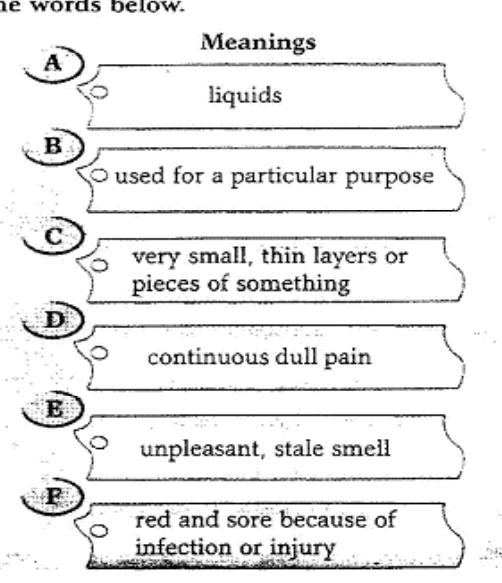

(b) Complete these sentences using the words above.

$1 \mathrm{He}$ always suffers from ... after a game of squash.

2 This is a ... cream. It is very effective for burns.

3 The doctor advised Helena to drink plenty of ....

4 The weather is so hot that the paint is peeling off in ....

5 She bought an air freshener to get rid of the unpleasant ... in the room.

$6 \mathrm{My}$ sister could not sleep last night because of the pain from her ... finger.

Tox

Figure 2: Highest Percentage White Space Page (93.71\%)

While the program is loading, glimpses of the assessed picture will become visible to users. The sample of post-run program, after folder path is inserted is demonstrated in Figure 3. 


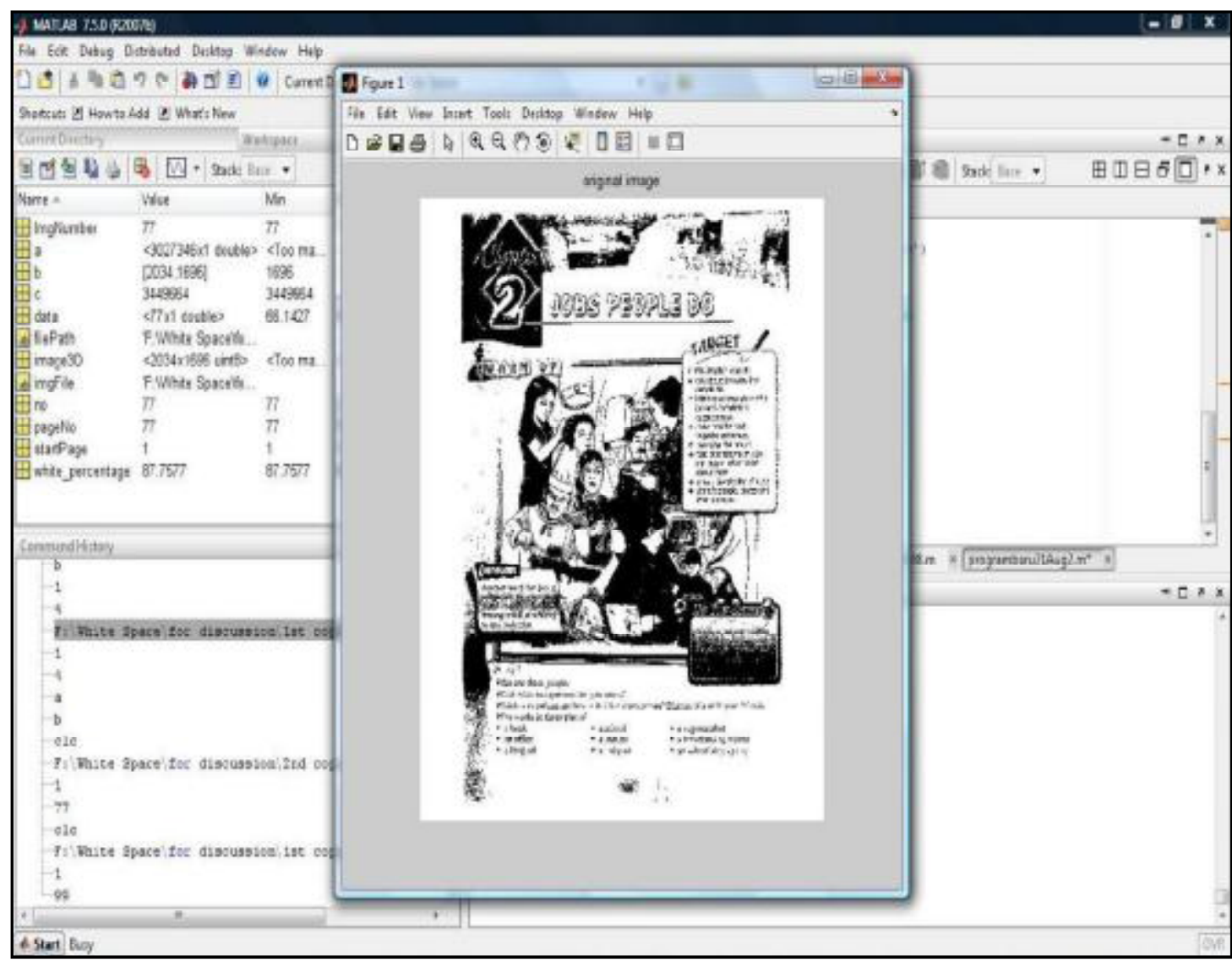

Figure 3: Sample of Executed Program to Obtain the White Space Percentage

This picture is the first page of Chapter 2, on page 14. The calculated white space percentage is $72.32 \%$. This value is rather low as this software is able to scrutinize every single pixel available on the page which is impossible to do with the naked eye. The accuracy of the image processing is undoubtedly accurate as this commercialized software is used worldwide to carry out image recognition and processing. The study of the white space can be done either in 2 or 3 dimensional form with pixels in terms of arranged matrices. To ensure the reliability and accuracy of the created program, the researchers have tested the written program in MATLAB 7.5 with additional scanned materials of completely 'white' material and completely 'black' material. If the program is correctly written and run, the 
results should yield zero $(0 \%)$ percentage for the completely 'black' material and one hundred (100\%) for the completely 'white' material. The obtained results are as follow.

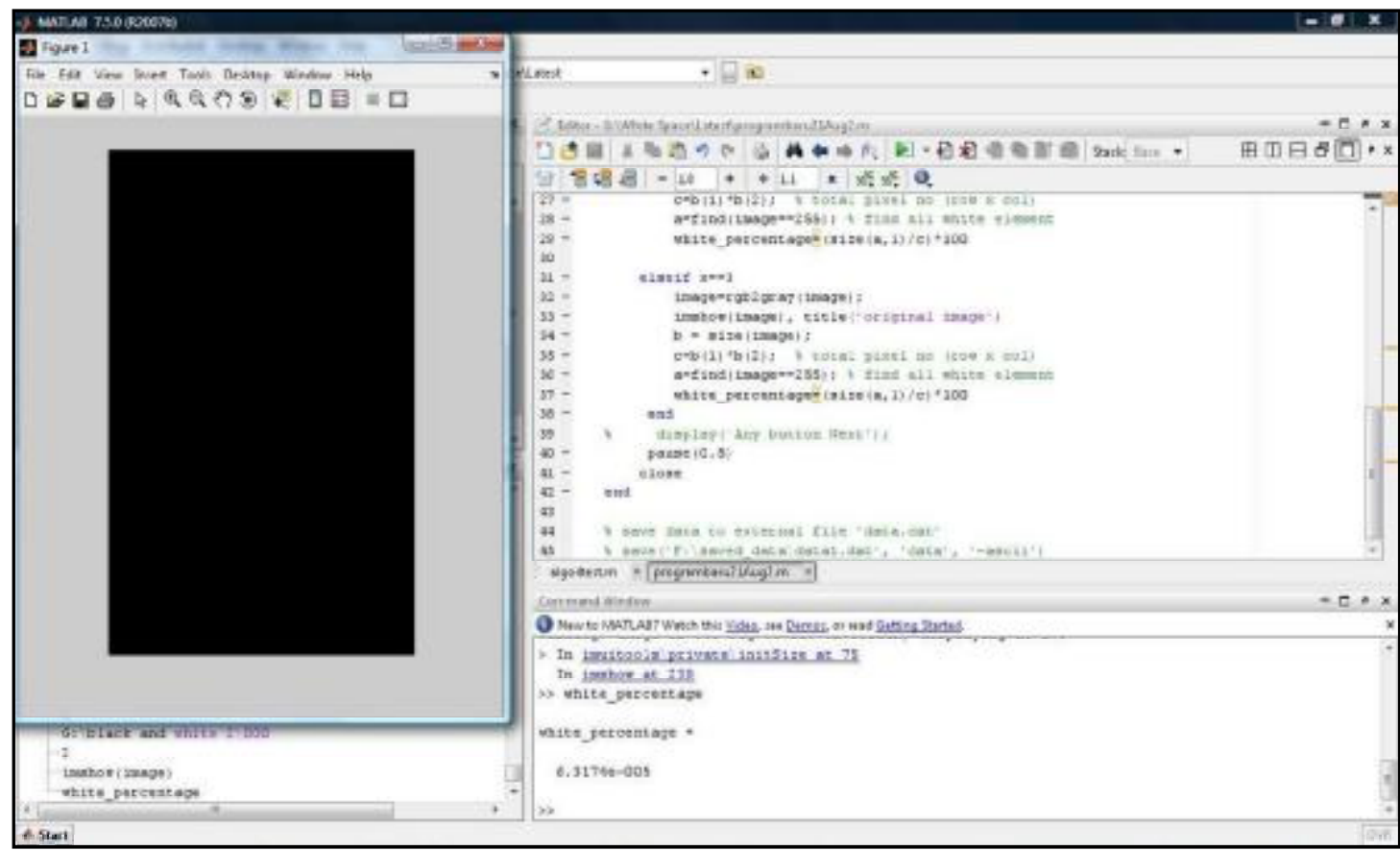

Figure 4: Analysis of Totally 'Black' Material

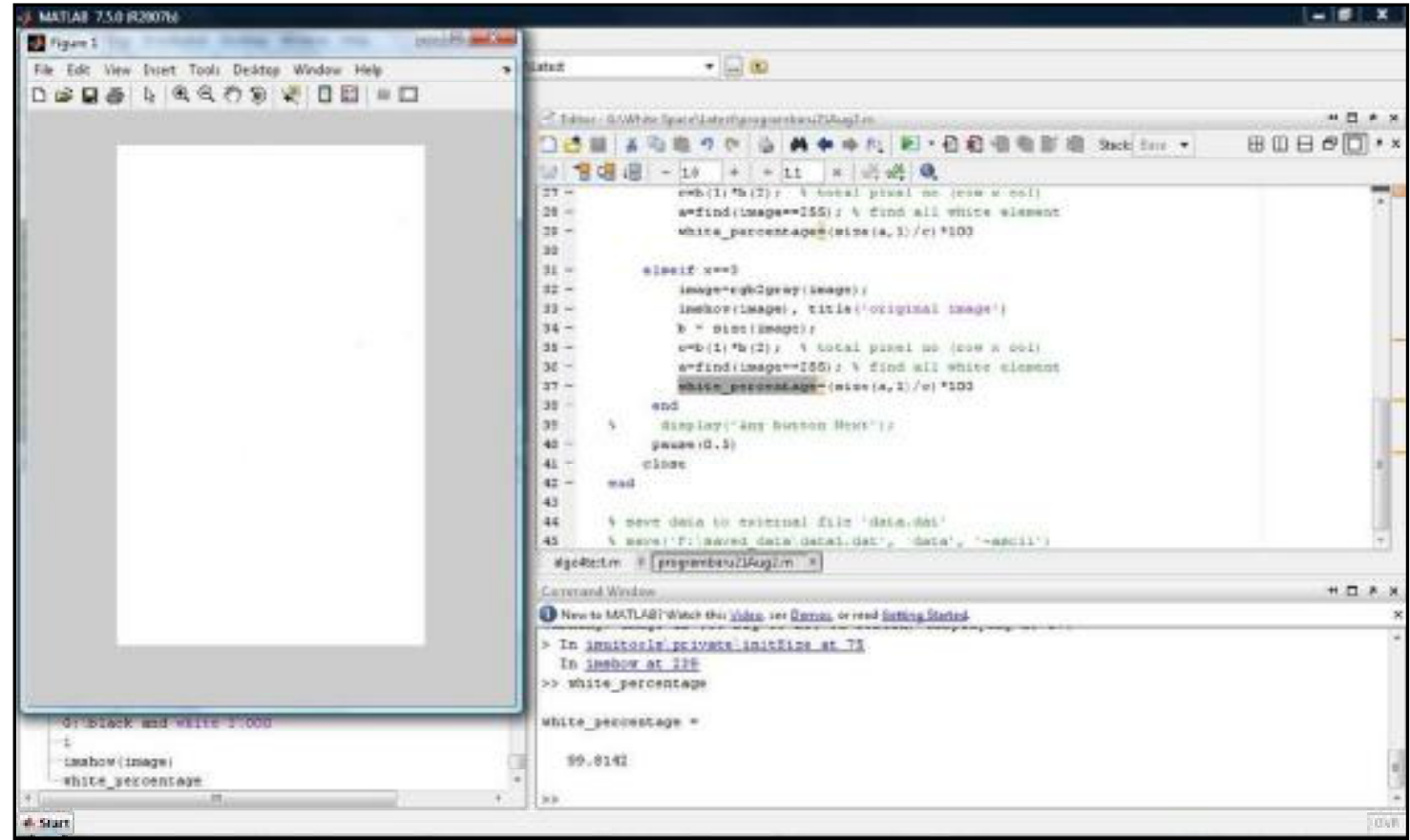

Figure 5: Analysis of Totally 'White' Material 
From the results, Figure 4, the completely 'black' or 'dark' material gives the value of $6.317 \mathrm{e}-005$. In other words, it reads as ' 6.317 exponential negative five' which yields the value of $0.00006317 \%$. The value is truly close to zero and it is so small that it can be neglected. The results shows the sensitivity and accuracy of the tool as a powerful evaluation image processing software that detects even the slightest 'noise' or unwanted marks on the page. This 'noise' or disturbance affects the final assessment of the amount of white space. Figure 5 clearly indicates that the percentage of the completely 'white' material is very close to one hundred percent. The result shows that the amount of white space on the page reads $99.8142 \%$. This result once again advocates the sensitivity and effectiveness of the software.

\section{Discussion on the Analysis Using MATLAB 7.5: The findings from the Textbook}

The analysis of white space properties in the textbook evidently proves that the percentage of white space in the material is truly inadequate. As advocated by Tomlinson (1998), more white space in the material can lower the learners' anxiety level. Besides ineffectiveness in vocabulary distribution throughout the textbook, the impromptu layout of the pages in the texts will alleviate students' interest in using the material as well as learning the language.

Based on some observations, the researchers have found that a percentage of $90 \%$ white space on a page can be less threatening. Only 30 out of 206 pages $(14.6 \%)$ in the textbook have percentages of over $90 \%$ white space.

MATLAB 7.5 is the latest version of MATLAB tool. This software is very reliable as it is used all over the world by researchers and engineers. However, the only difficulty in using this software is that users ought to learn some C- 
programming language skills in order to perform the execution. MATLAB is a foreign tool in the ELT world as this software involves evaluation of number, formulas and programs. Only engineers and programmers use this software in their field to move a machine or to encode or decode data. However, the results show that this software can be used to evaluate white space on paper in terms of pixels. From the findings of the percentage of white space in the textbook, a general inference can be made. The higher the percentage of white space the better is the page in facilitating clarity and lowering of learners' anxiety level.

\section{Conclusion}

MATLAB is the software used to screen and process images in the field of engineering. It is now also an innovative tool to evaluate white space on pages, with some help from programming language. With the use of MATLAB, educators can now assess the amount of white space in textbooks. Educators can now use the software to ensure that pages in textbooks are learner-friendly. 


\section{References}

Arnold, J. (1999). Affect in Language Learning. Cambridge University Press.

Arshad Abdul Samad \&Nooreen Noordin (2005). Examining the Importance of EST and ESL Textbooks and Materials: Objectives, Content and Form. Retrieved March 6, 2008, from http://esp-world.7p.com/Articles_9/textbooks.htm

Brown, D.H. (2001). Teaching by Principles, An Interactive Approach to Language Pedagogy (2 ${ }^{\text {nd }}$ ed). San Francisco: San Francisco State University.

Canfield, J. \& Wells, H.C. (1994). One hundred ways to enhance self-concept in the classroom. NY: Allyn \& Bacon Pub.

International ELT Materials Conference $\left(3^{\text {rd }}\right), 16-17$ October 2008, Melaka Historical City, organized by Universiti Teknologi MARA, Melaka.

Kementerian Pendidikan Malaysia (2008). Panduan Buku Teks. Retrieved April 2, 2008 from http://www.moe.gov.my

Mukundan, J. (2003). State-sponsored textbooks: Are there hidden costs in there "free" books? The English Teacher, 6(2), 133-143.

Mukundan, J. (2003). The Development of a Composite Framework for Textbook Evaluation. In J. Mukundan (Ed.), Readings on ELT Materials (pp. 61-68). Serdang: UPM Press.

Mukundan, J. (2006). Are There New Ways of Evaluating ELT Textbooks? In J. Mukundan (Ed.), Readings on ELT Materials II (pp. 170-180). Petaling Jaya: Pearson Malaysia.

Mukundan, J. (2006). ELT Materials: Do Policy and Implementation Reflect Pedagogic Sense? In J. Mukundan (Ed.), Focus on ELT Materials (pp. 39-43). Petaling Jaya: Pearson Malaysia.

Ricardo, S. (2007). Stephen Krashen's Theory of Second Language Acquisition. Retrieved March 24, 2008, from http://www.sk.com.br/sk-krash.html.

Skierso, A. (1991). Textbooks Selection and Evaluation. Boston: Heinle \& Heinle.

Stoller, F.L., \& Grabe, W. (1995). Implications for L2 vocabulary acquisition and instruction from L1 vocabulary research. Norwood, NJ: Ablex Publishing Corporation.

Tomlinson, B. (2005) The Future for ELT Materials in Asia. Electronic Journal of Foreign Language Teaching, 2 (2), 5-13.

Tomlinson, B. (1998) Materials Development in Language Teaching. Cambridge: Cambridge University Press. 